International Journal of Computer Graphics \& Animation (IJCGA) Vol.2, No.4, October 2012

\title{
Assessing the Impact of Technological \& Cultural Elements of the i-CLAP Model Design on Pre- Primary School Children in Zaria
}

\author{
Joseph Izang, Azi (Ph.D.) \\ College of Imaging Arts and Sciences, Rochester Institute of Technology (RIT), \\ Rochester, New York \\ $\&$ \\ Department of Industrial Design, Ahmadu Bello University (ABU), Zaria, Kaduna State \\ azijoe86a2000@yahoo.com; jia7050@g.rit.edu
}

\begin{abstract}
Developments in technology are more than ever before enabling the creation of remarkable ComputerAssisted Instruction (CAI) resources for enriching and transforming the educational environment in the $2 I^{\text {st }}$ century. This progress is considered indispensable for Nigeria in the wake of declining school enrollment, high dropout rate and low learning achievement levels. Hence, relevant especially if such a predominantly traditional (face-to-face) educational system must be revolutionized to meet contemporary needs and techniques. Therefore, while this article argues for the integration of technology hardware and software into the local education environment, it however emphasizes the need to develop custom instructional resources that integrate local folkloric contents pertinent to Nigeria's educational philosophy and cultural socialization. The Interactive Child Learning Aid Project (i-CLAP) model is initiated as a potential indigenous CAI model for application in the local pre-primary school curriculum. The impact of implementing the model's concept within $(N=4)$ selected pre-primary schools in Zaria - Kaduna State is examined. The researcher used 'classroom observation' for data gathering and Pearson Product Moment Correlation $(r)$ and $t$-Test for analyzing the on-task and off-task classroom behaviors of $(N=80)$ pupils. Thereby, revealing valuable lessons on the project's potential as a techno-cultural resource for reinforcing motivation and interest among pre-primary school children in Nigeria. Recommends for its integration into the educational curriculum is made, towards facilitating the attainment of the UBE and MDGs agendas.
\end{abstract}

\section{KEYWORDS}

Design, Technology Intervention, ECD, Culture, Instructional Multimedia

\section{INTRODUCTION}

Developmental challenges such as the population explosion, rural-urban drift, political instability, poor policy formulation, deplorable social amenities and shrinking economy have exerted constraints on educational development in Nigeria. Wherefrom, problems such as: underpaid teachers' salaries, inadequate classrooms, lack of teaching and learning facilities among others, have lingered for decades. According to Nwachuku [22] education has been badly affected by structural adjustment program (SAP), with institutions at all levels too ill equipped in terms of physical facilities and recurrent funds to serve their educational purpose with any degree of credibility. Leading to disparities in the educational system, including those between: (i) urban

DOI : 10.5121/ijcga.2012.2401 
and rural schools; (ii) public and private schools; (iii) male and female enrolments and (iv) admission figures and commensurate instructional resources. Igbuzor [9] sums it up as "declining literacy rates in the country."

The consequence of which is a deplorable educational system characterized by declining enrollment, high dropout rate and low learning achievement levels, hence unable to deliver valuable dividends to the teeming populace. Making quality early childhood care and education (ECCE) to remain a luxury for most Nigerian children. Additional to the problem of dilapidated infrastructure are the lack of curricular update and obsolescence in instructional resources. The Association for the Development of Education in Africa (ADEA) affirms that in modern SubSaharan African societies, the major agent implementing the process of education has been the traditional education system, featuring: face-to-face (chalk-and-talk) interaction between teachers and learners, structured courses, fixed location, fixed periods and so on [1].

Nordhoff [21] ascertains that worldwide, politics, social and economic structures are changing at an ever-increasing rate, these places an increasing strain on the educational systems that have to prepare learners for their roles in an ever-changing society. The challenge therefore, is that early childhood development (ECD) programs in Nigeria must pay unwavering attention to enhancing learners' motivation and interest. Below are seen images of children having the African experience: while the first (Figure 1a) shows learners in a face-to-face under-the-tree classroom interaction with teacher and (Figure 1b) shows children taking a jolly bicycle ride. Hence, social engineers like teachers, educational administrators, instructional designers and technologists today, cannot succeed in their advocacy ambition unless they are able to rethink and fine-tune their vocational methods to meet the changing demands of globalization.
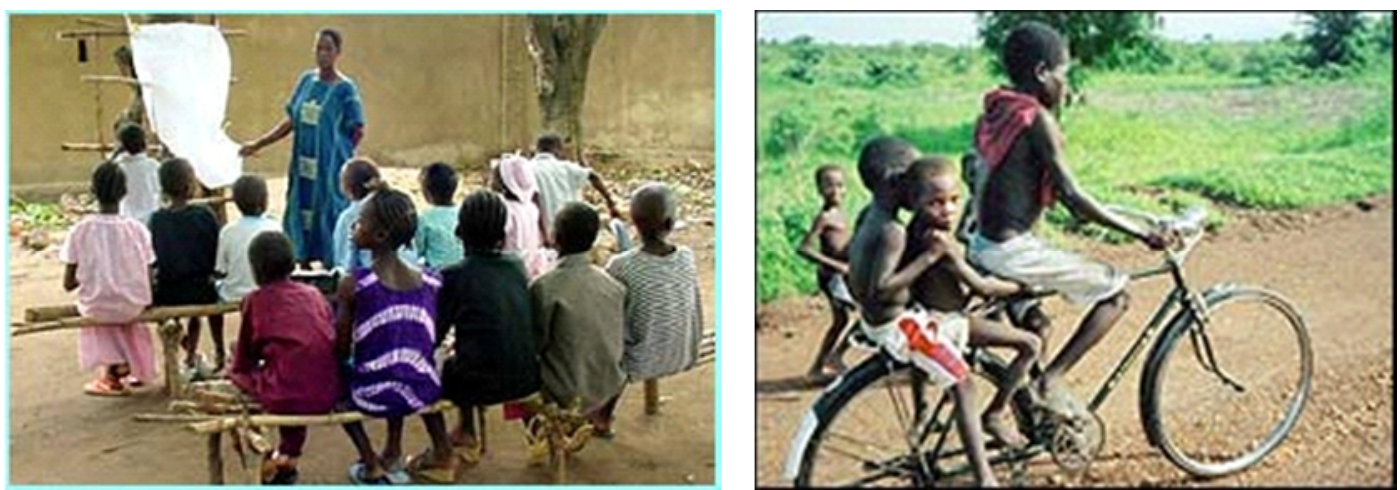

Figure 1: Children having the African Experience: (a) a face-to-face under-the-tree classroom interaction with teacher and (b) Taking a Jolly Bicycle Ride

There is the need to build the skills required to provide a platform for smooth transitioning from home to school (i.e. school-readiness) among Nigerian children, towards reinforcing life-long learning achievements. This according to Azi [3] can be done through focusing on a learning strategy that combines education, entertainment and lifelong skills; which can be availed by instructional multimedia technologies. Martins [12] and Azi [4] affirm that the advent of computer-assisted instruction (CAI) has impacted the educational environment much more than earlier technologies such as print, radio, telephone, audio-visual ever did, especially towards stimulating greater motivation in the learning process and enhancing academic achievement. Chambers and Sprecher [5] maintain that computers are used to assist in the learning situation through simulation, game, tutorial or drill and practice mode and have their centers of activity 
identified to be the United States, Canada, United Kingdom and Japan. Research reveals that the pedagogical proficiency of technology-mediated resources on cognitive development supports self-directed learning, collaborative project work, exploratorium and global understanding. McNutt [15] affirms that computer-based learning enhances performance in areas that include:

- Reduction in instructional time

- Stimulates in learners a more positive attitude towards the learning process

- Can be more cost effective in some circumstances

- Supports self-paced/individual learning

- Offers variety of presentation options to developers

- Proffers interactivity (response-producing stimuli) of courseware and

- Facilitates student's intellectual management abilities.

According to Kinyanjui [10] the NEPAD e-Africa Commission's mandate is to manage the structured development of the ICT sector on the African continent, hence required to develop broad strategies and a comprehensive action plan. Hence, in 2003, the Commission presented a list of six ICT projects as high-priority, among which were the NEPAD e-schools Satellite Network; teacher training and content development. This underscores the significance of technology integration in education as paramount to Africa's development and future. According to Morse [17] motivated students of the very highest ability in technology environments might learn at three to four times the average classroom rate.

However, beyond technology there is the need to integrate relevant components of the target audiences' cultural norms and values. The world Education Ministers declare affirmatively that "Quality Education" should embrace certain basic knowledge, values, competence and behavior specifically attuned to globalization, but reflect the beauty and riches of our diversity expressed in different forms of belief, culture and language [26]. Against which backdrop, Azi [5] recommends that positive aspects of cultural heritage should be harnessed using digital technology resources and garnered into relevant contents and interfaces for local applications. In view of which a techno-cultural initiative was proposed in 2002 dubbed the Interactive Child Learning Aid Project (i-CLAP), as an indigenous instructional multimedia model for enhancing pre-primary education in Nigeria. The goal of the initiative therefore is to develop a contemporary educational philosophy that hybridizes essential instructional technology concepts, through establishing a logical link between:

(i) Early Childhood Educational Development in Nigeria

(ii) Computer-Assisted Instructions (CAI) (vis-à-vis traditional methods)

(iii) Child cultural socialization

(iv) Nigeria's rich cultural heritage (e.g. folklores, music, crafts, fashion etc.)

(v) Local (Digital) Content Development

The initiative is premised on the fact that if "education is life itself" as advocated by John Dewey (1859-1952) the American philosopher, psychologist and educator [19], then the African child desperately deserves the right to life. In fact, not just any kind of 'life', but 'a good and fulfilling life'. Literacy is seen to play a key role in the achievement of a modest productive life and the freedom to quality education derived from the most appropriate blend of strategies. This article therefore is to assess the technological and cultural impact of the i-CLAP model design as an 'indigenous' initiative, which was pilot-tested in Zaria - Nigeria. European Commission [8] 
asserts that impact assessment connotes a set of logical steps which helps to assess potential economic, social and environmental consequences of new initiatives they propose, which provides evidences for political decision-makers on the advantages and disadvantages of possible policy options. The impact of the i-CLAP model's pilot-test on the cognitive performance of local pre-primary school children was evaluated, as well as its potential to be integrated into the Nigerian education curriculum.

\section{INTEGRATING MULTIMEDIA TECHNOLOGY \& CULTURE}

Multimedia technology entails the use of computers and other co-operational classroom peripherals that include: LCD projector, digital camera, iPod, television and video, laptop, MP3 recorder, game console, palmtop, joystick, camcorder, earphone and e-learning and teleconferencing enablement etc. Figure 2 (below) shows various forms of multimedia: (a) shows children in a rich multimedia environment; (b) multimedia as combining multiple technologies like camcorder (video camera), still camera, animation, text and so on and (c) software for learning the alphabets called "Blue's ABC Time Activities". Evidences of the effectiveness of instructional multimedia technology as enrichment resources in the $21^{\text {st }}$ century can be seen in the application of computer hardware integrating appropriate software programs that enable interactive simulation. Such programs include: Sesame Street, Disney Interactive, Blue's Clues $\mathrm{ABC}$, Mickey Mouse Toddler, Mind Power and so on.
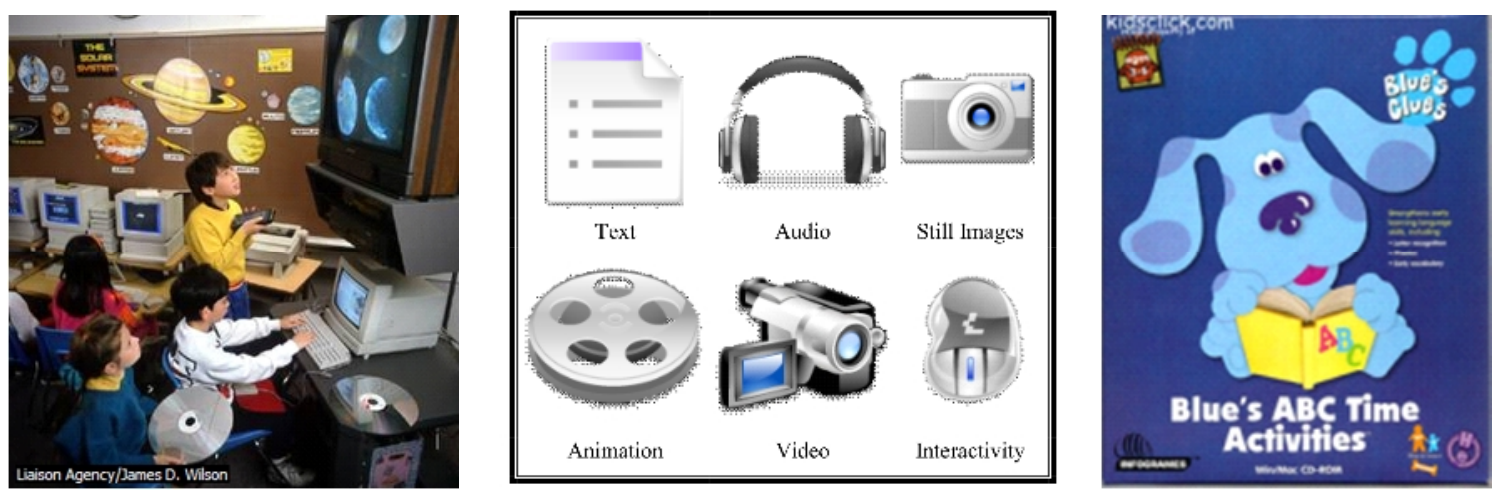

Figure 2: Multimedia (a) Children Using Multimedia, (b) Multimedia as Combining Multiple Technologies \& (c) Appropriate Software like Blue's ABC Time Activities

Jeanne S. Chall in a preface to the book Learning to Read in the Computer Age ascertains that it is hard to find a proposal for improving American education that does not include plans for the widespread use of computers [16]. However, it is noted with serious concern, that such software contents required for the implementation are specifically designed and developed to satisfy the needs and interests of the American audiences. Also, possible for adoption by other dominant international cultures like Britain, Canada, France and Japan and so on, unfortunately with little or no regards to minorities like Africa and other less developed nations. McLoughlin [14] highlights the following among factors liable to constitute barriers in this regard:

(i) Problems of culture and environment;

(ii) Teaching style differences;

(iii) Problems relating to different educational values;

(iv) Problems of language and semantics; 
(v) Technical problems relating to platforms, operating systems and lack of standard interface.

Therefore, the need cannot be disputed for 'contextualization' of such educational technology contents, to ensure unimpeded communication and optimal effectiveness, especially with regard to those meant for non-western and non-technologically advanced regions such as Africa. This task therefore would entail the integration of local contents into the design and development of such intervention resources. Okpaku [23] affirms that the challenge is to develop local contents, based especially on Africa's cultural legacy. Also, Kinyanjui [10] stresses that such contents, where possible, should accommodate the cultures of its users by being in their local languages, towards ensuring that Africans are not just consumers of contents developed elsewhere but also originators and creators of their own content. So far, several minority societies have since initiated efforts towards developing contextualized educational resources: a few examples among such include: 'Meena' in India; 'Si Unyil' (The Boy) in Indonesia; 'Mixy's Toybox' in Australia to mention only a few projects.

It is noted that the task in Australia was to design culturally inclusive and educationally effective schools, to make the achievement of educational equality for 'indigenous peoples' an urgent national priority especially in early childhood education [25]. Similarly, MCEETYA [13] affirm that the "Model of More Culturally Inclusive and Educationally Effective Schools" is based on a number of findings from recent work to improve the nature of schooling and educational outcomes for students. Adding further, the model is designed as a means of creating sustainable change and improvement that integrates the successful outcomes of indigenous programs into mainstream schooling practice with focus on: community, school and classroom. This strategy is seen according to Kronemann [11] as being flexible and more responsiveness to local needs rather than 'one-size-fits-all' approach.

Karin Hyde and Margaret Kabiru argue that ECD interventions in Africa are more successful when built on local knowledge [24]. Consequently, the local adaptation of Sesame Street programs began to be introduced into Africa, beginning from South Africa (as Takalani Sesame), Egypt (as Alam Simsim) and to Nigeria (Sesame Square) [7]. What is exceptional about the initiative is the incorporation of local contents such as the target audiences' cultural values, languages, learning styles, using "homegrown characters" to educate while entertaining audiences. They also address peculiar local needs, like Kami, a mustard-colored furry HIV infested Muppet in South Africa, who educates children on the AIDS/HIV scourge in Africa [18]. The program also features famous local personalities, making it really indigenous. Njanji [20] considers it as having "a definite African twist." Which is seen as positive in the light of cultural content integration and application in relevant educational application platforms.

Therefore, by acquiring inspirations from such initiatives given the ample opportunities proffered by technology and the rich apparatus of indigenous folklores, music, art, crafts, fashion etc., Africa can developed its own 'unique' ECD enrichment program contents. Especially, such that would be much more applicable to its local educational configuration and practices, cultural socialization and national development philosophies and needs. This, it is supposed, would go a long way in enhancing human capacity building, sustainable development and most of all the preservation, promotion and projection of Africa's rich heritage. In addressing this significant quest therefore, the design and development of an 'indigenized' instructional multimedia model for Nigeria was initiated in 2002 as a Doctoral Degree research, called the Interactive Child Learning Aid Project (i-CLAP) model. 
International Journal of Computer Graphics \& Animation (IJCGA) Vol.2, No.4, October 2012

\section{THE i-CLAP MODEL DESIGN STRUCTURE}

The i-CLAP model design was carried out using the ADDIE model structure, which proffers 5 steps to instructional design namely: Analysis, Design, Develop, Implement and Evaluate. In line with this structure, the processes of the i-CLAP model development were broken down into 3 milestones:

1. (i) Need Analysis (i.e. identifying and evaluating needs)

(ii) Design (i.e. structuring necessary parameters)

2. (iii) Develop (i.e. producing the practical component of the model)

3. (iv) Implementation (i.e. testing the effect of the model on the target audience) and

(v) Evaluation (i.e. analysing results of test on audience)

Of course, while the first year of the Ph.D. research was strictly dedicated for the coursework, which Azi [5] affirms is a prerequisite for all Graduate and Postgraduate students at the Department of Industrial Design, ABU Zaria. The analysis and design phases for the research were carried out mainly between 2003 and 2005. However, between 2005 and 2006, the initiator of the project (Joseph Azi) was awarded the Fulbright Junior Staff Development (JSD) Grant (No. 15054524), administrated by the Institute of International Education (IIE), New York. Wherefrom, state-of-the-arts Computer Graphics and Animation facilities were used to develop the practical components of the i-CLAP model, at the School of Design, College of Imaging Arts and Sciences (CIAS), Rochester Institute of Technology (RIT), Rochester, New York. The developed model served as a fundamental component of research instruments used during the pilot test.

\section{IMPLEMENTATION OF THE i-CLAP MODEL IN ZARIA}

Designing and developing a 'contextualized' instructional resource for Nigeria has become necessary, given the fact that western packages are targeted at a cross-cultural dominant majority cultures like America, Canada, France and so on. Consequently, limiting the capacity of such resources to provide culturally inclusive learning experiences to minority audiences, towards meeting adequate local learning and cultural socialization needs. This article reports the implementation of the i-CLAP model in Samaru, Zaria and evaluates its effectiveness as a potential indigenous technology-mediated resource for Nigeria. Especially, towards complementing the predominantly traditional teaching and learning methods in pre-primary school learning delivery. The report documented notable observations acquired on the impact of technology on children's problem solving ability, classroom behavior, reflective thinking and cognitive development.

Methodology: Formative evaluation was the research method adapted for the i-CLAP model development which involving data gathering, testing and evaluation. The practical component of the research instrument was developed using the state-of-the-art Computer Graphics and Animation facility at the School of Design, College of Imaging Arts and Sciences, Rochester Institute of Technology, Rochester, New York. This privilege was made available through the Visiting Research Grant (No. 15054524) awarded by the Fulbright Junior Staff Development (JSD) of the US Department of State for Education. Consequently, the model was tested in Nigeria for 4 weeks (starting from $17^{\text {th }}$ of July, 2006), among 80 randomly selected children of 56 years. 
Sampling: The sampled population (selected using 'purposive sampling') constituted pupils from 4 pre-primary schools, with 40 for the 'control' and 'experimental' groups each. The schools were selected through 'stratified random sampling' in order to represent the rural and urban settings, two schools therefore emerged from both ABU Main Campus and Samaru Village within Zaria in Kaduna State. Table 1, below shows the distribution of schools by number of pupils and teachers:

Table 1: Distribution of Schools by Number of Pupils (Experimental \& Control groups), Percentage and Teachers

\begin{tabular}{|c|c|c|c|c|c|c|}
\hline $\mathbf{S} / \mathbf{N}$ & $\begin{array}{l}\text { Name of Pre- } \\
\text { Primary School }\end{array}$ & $\begin{array}{l}\text { No. of } \\
\text { Control } \\
\text { Group }\end{array}$ & $\begin{array}{l}\text { No. of } \\
\text { Experimental } \\
\text { Group }\end{array}$ & $\begin{array}{l}\text { Total No. } \\
\text { of Pupils }\end{array}$ & $\%$ & $\begin{array}{c}\text { No of } \\
\text { Research } \\
\text { Assistants } \\
\text { (Teachers) } \\
\end{array}$ \\
\hline 1 & $\begin{array}{l}\text { ABU Staff School, } \\
\text { ABU Main Campus, } \\
\text { Samaru - Zaria } \\
\end{array}$ & 10 & 10 & 20 & 25 & 2 \\
\hline 2 & $\begin{array}{l}\text { Sa'idu Model School, } \\
\text { Samaru - Zaria }\end{array}$ & 10 & 10 & 20 & 25 & 2 \\
\hline 3 & $\begin{array}{l}\text { The Foundation Model } \\
\text { School, Samaru - } \\
\text { Zaria }\end{array}$ & 10 & 10 & 20 & 25 & 2 \\
\hline 4 & $\begin{array}{l}\text { Vital Years Nursery } \\
\text { and Primary, ABU } \\
\text { Main Campus, Samaru } \\
\text { - Zaria }\end{array}$ & 10 & 10 & 20 & 25 & 2 \\
\hline Total & 4 & 40 & 40 & 80 & 100 & 8 \\
\hline
\end{tabular}

From the tabulation on Table 1, a total of 80 participants were involved in the test, with 20 from each school representing $25 \%$ of the subjects. A total of 8 teachers from the 4 schools were also selected to serve as research assistants.

Procedure for Data Collection: The data collection procedure for this research was carried-out from two classes of subjects: the 'experimental' and 'control' groups which were conducted within two separate sites. While the experimental group's test centre was located at the Iya Abubakar Computer Centre (IACC), ABU Zaria, the control group test were conducted within the participating school classrooms. Although the control group used traditional resources to conduct English language alphabets, word pronunciation and picture/color recognition activities. The experimental group used colorfully rendered multimedia resources, built with realistic speech and self-testing and dynamic feedback devices. To complement the learning activities for the experimental group, the i-CLAP modules also included artistic activities in "object coloring" using the "creative tools", equipped with a range of colored brushes to pick from and paint with all in form of games as seen in Figure 3 (below). A typical i-CLAP technology-mediated classroom session is seen below in Figure 4. The pilot-test activities were conducted using a lesson plan developed solely for the programs.

The computer-generated components were designed in line with the assertion by Amory, Naicker, Vincent and Adams (1999), that play associated with games, especially during early childhood, performs important roles in psychological, social and intellectual development. It is noteworthy 
International Journal of Computer Graphics \& Animation (IJCGA) Vol.2, No.4, October 2012

that skills required for playing such computer-generated games included logic, memory, visualization and problem solving such that promotes goal formation and competition. According to Azi [3] the goal however, was not only to stimulate cognitive concept development, but to also bring the application of information and communication technology (ICT) closer to the grassroots as pedestal for participation in the $21^{\text {st }}$ century. This being an unquestionable challenge that Nigeria must face given that it had only recently unfolded a new UBE agenda as part of its Millennium Development Goals (MDG) implementation plans. Thus, in developing this model the researcher adapted a new art technique called "Afrimation" (i.e. African animation), composing of African art and design, child art and caricature, Computer Graphics and Animation. The rationale for adapting this new technique was to enhance easy recognition, assimilation and recall among the local children being the target audiences.

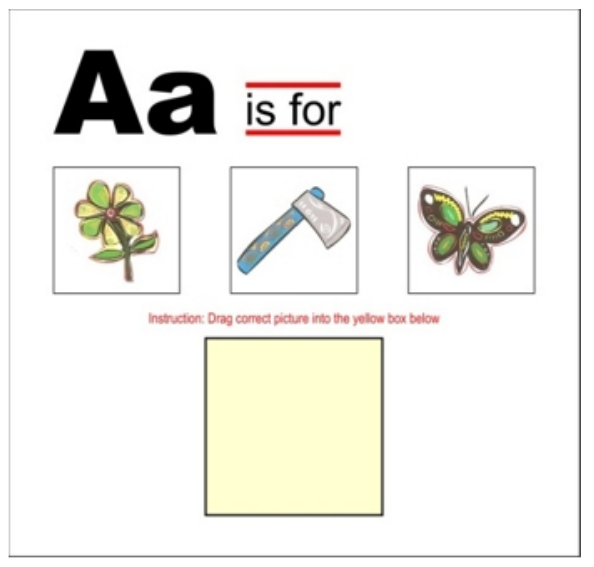

Figure 3: Wazobia: the African Boy (i-CLAP Model's Linear Clip) \& Match-Pictures-toAlphabets (i-CLAP Model's Interactive Game) (2005)

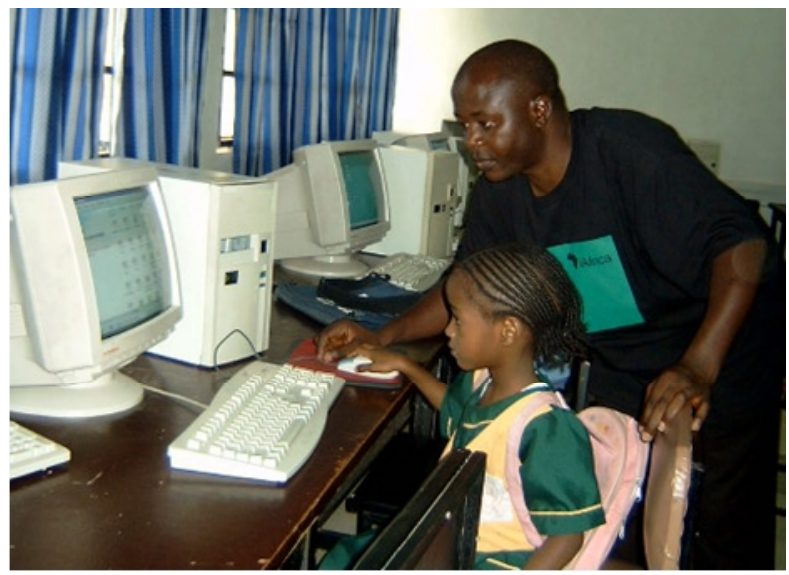

Figure 4: An i-CLAP Student and the i-CLAP Model Project Initiator (Dr. J. I. Azi) in a Class Session Playing the Games on a Desktop Computer

Instrumentation: The instrument considered for the i-CLAP model implementation was "classroom observation" carried out with a view to evaluating students' classroom behavior using 3 instruments testing their aptitude namely: 
International Journal of Computer Graphics \& Animation (IJCGA) Vol.2, No.4, October 2012

(i) Written tests (carried out Weekly)

(ii) Drawing assignments (Daily take-home) and

(iii) Assessments in using Computer-Assisted Instruction (Daily)

Since it is believed that when computers are used with children in preschool, pre-primary or childcare settings, the computer should be one of many activity choices they can explore freely, the i-CLAP model was designed to proffer 4 different educational game modules to choose from. Moreover, that children's attention span is said to be short and that they frequently use computers for short periods and then they become interested in another activity. Daily lessons spanned for an average of ninety minutes, carrying series of activities that included: role calls, collection of home-works (at the beginning), issuance of take-home assignments (at the end), tutorials, weekly tests and questions and answer sessions.

\section{RESULTS, OBSERVATIONS AND FINDINGS}

An analysis of the effectiveness of the i-CLAP model was carried out with weekly comparisons of the children's assessments in order to identify changes in both their classroom behaviour and learning performances as follows:

(a) Results: An assessment of the differences between the learning ability of pupils adapting the i-CLAP Model and those using the traditional face-to-face teaching and learning delivery in Nigeria is revealed through the following quantitative data:

Table 2: Comparison between Pupils Cognitive Performance Using the Customized i-CLAP Model and Traditional Teaching \& Learning Methods

\begin{tabular}{|l|l|c|c|c|c|c|c|c|c|}
\hline Variable & $\mathrm{N}$ & Mean & $\mathrm{SD}$ & $\mathrm{SE}$ & $\begin{array}{l}\text { t-value } \\
\text { Calculated }\end{array}$ & df & $\begin{array}{l}\text { t-value } \\
\text { critical }\end{array}$ & P-value & Decision \\
\hline Public & 120 & 13.43 & 2.84 & 0.26 & \multirow{2}{*}{16.71} & 238 & 1.96 & 0.001 & Significant \\
\cline { 1 - 8 } Private & 120 & 7.33 & 2.82 & 0.26 & & & \\
\hline
\end{tabular}

Using t-test, the analysis of the difference between adapting the i-CLAP model and traditional teaching and learning methods (face-to-face) in Pre-primary school teaching and learning delivery in Samaru, Zaria Kaduna State, shows that the calculated t-value of 16.71 was lower that the critical $t$-value of 1.96. This indicates that there is significant difference, at $\mathrm{P}<0.05$ confidence level, between the performance of children who used the i-CLAP model and those who used the traditional method. The result reveals therefore, that the use of the i-CLAP model appeared to have played a significant role in enhancing the pupils' performance. Their mean scores were 13.43 as against 7.33 implying that they had performed better than their counterparts who used the traditional methods.

(b) Observations: On the other hand a lot of observations were recorded from the children's ontask and off-task behaviors, most of which have the potency to support the domains of learning (i.e. affective, psychomotor and cognitive - developed by Benjamin Bloom): 
- Affective (Feeling): Outstanding attitudes among the participants included the accordance of high value to the program and the willingness to actively participate in the learn process. Although, they felt more secured with adult facilitators, they helped each other in moments of difficulty and shared the joy of discovering something new devoid of their differences. This was contrary to speculations that the computer environment was inhibitive leading to social isolation. In further, records were set of participants' experiencing emotional outburst in manners that included:

(i) Singing: This was carried out by a female participant as she played one of the interactive games. In a subtle voice she synchronized a native song as she tapped the keyboard to move the arrow in the 'find-the-alphabet' game;

(ii) Crying: Crying was recorded only three times among participants: while the first felt angry for being brought to class about 15 minutes late by her father; for the second his father was unable to name the $4^{\text {th }}$ and $5^{\text {th }}$ objects that began with the letter 'I' (that is after: iron, ice-cream, ink); the last kid cried because his friend snatched the cellophane bag used for carrying his project resources.

Generally speaking, participants expressed a feeling of great excitement and fulfilment for the privilege to participate in the program; exhibiting worthy behaviors like: tolerance, punctuality, respect, kindness, companionship, honesty and integrity. Feedback from teachers and parents was positive, seeing the overwhelming enthusiasm displayed by their wards.

- Psychomotor (Doing): This domain deals with manual manipulation by repeating the examples given by instructor, practicing towards competence and acquiring automatic skill (muscle memory). Such that children who ordinarily had not prior experience on the computer, were able to use the mouse and adapted swiftly to the hand-eye coordination required for operating the computer system. This was amazing to research assistants (most of whom were their teachers) who comparatively took much longer to overcome their initial phobia during the train-the-trainer workshop.

- Cognitive (Thinking): This involved drills, memorization and recall, interpretation, application of information to real-life situations, analyzing meaning and making new knowledge. The children's ability to make the most of their participants within the very short period of 4 weeks was awesome. Such that at the end they could start the computer, identify relevant icons, open, play and close the games and shot the system. Perhaps, from such experiences emanated evidences of their ability to apply knowledge analytically triggering the following questions and comment:

(i) Big Computer on the Wall - A pupil asked "Does the wall of Iya Abubakar Computer Centre have a big computer on it?" That was after the first tutorial when a multimedia projector was used to project the modules on a $9 \mathrm{ft} \times 12 \mathrm{ft}$ scale surface.

(ii) Design for Us Another Game - The other was a requested placed after weeks of playing the games: that since 'Match Pictures to Alphabets' is about ABCD, can you design for us another game using 1234? Though the comment may also signal the feeling of boredom, having exhausted all the games. Implying that the kids flourished better with more varieties of games that provided different kinds of stimuli. 
International Journal of Computer Graphics \& Animation (IJCGA) Vol.2, No.4, October 2012

(iii) ' $\mathbf{C}$ ' is for 'Chicken' - In a public demonstration to parents and guests organized at the end of the 4 week training, a participant having successfully listed two out of three items that began with ' $\mathrm{C}$ ' on the alphabet module (and having forgotten the $3^{\text {rd }}$ item on the module), spontaneously yield ' $\mathrm{C}$ ' is for 'chicken' which was not originally in the i-CLAP design that was used in instructing them. Also, a girl who was not included among the 10 selected to participate in the public demonstration, raised her hand persistently requesting to be permitted to carry out one of the tasks. Of course, it was an opportunity the MC could not deny offering her. This was evident that participants felt bolder and more confident.

(c) Findings: These qualitative and quantitative data assisted in justifying the information required, in view of which the following findings emerged:

As a technology-mediated instructional resource, the i-CLAP model project revealed the potential to attract local participants, hold their attention and stimulate greater learning interest and motivation in the learning process;

(ii) The use of Afrimation art and design techniques provided culturally inclusive visual and aural cues pertinent to participants' local socio-cultural situations, hence showed the tendency to engage, entertain and educate learners;

(iii) It was discovered that although CAI resources revealed high potential to reinforce learning motivation among local children, however to successfully operate the $21^{\text {st }}$ century classroom, technology training was required for teachers to manage the specialized facilities (i.e. hardware and software).

\section{CONCLUSION}

In view of the fact that in Nigeria where low school enrollment, high dropout and low learning achievement characterize the educational system, technology integration in education has been seen to enhance learners' motivation and interest. However, it is noted that when technologymediated contents are developed with contextual components meaningful to the learners' local experience and used appropriately by skilled teachers, has the potential to support cognitive development. The i-CLAP model which was designed and developed as an indigenous resource pertinent to Nigeria, demonstrates the efficacy of cultural integration for localized contents. Fundamental lessons emerged from the project implementation in Samaru - Zaria, which adapted the results of written tests, drawing assignments and assessments in using CAI towards evaluating the cognitive performance of pre-primary school children. The research further revealed that technology-mediated resources were flexible learning tool, capable of enhancing motivation and simulating greater learning engagement in children by holding their attention and interest. The research concluded that more than just supplying computer hardware in schools, the need to design relevant indigenous software contents could not be overemphasized. Especially, if the goal is towards proffering a medium for enhancing technology integration in advancing the UBE and MDGs agendas required to take Nigeria into the $21^{\text {st }}$ century.

\section{RECOMMENDATIONS}

The following recommendations are drawn: 
International Journal of Computer Graphics \& Animation (IJCGA) Vol.2, No.4, October 2012

- Current standards in instructional multimedia design theory and practice should be adapted towards creating contextualized resources that integrate African Indigenous Knowledge (AIK) concepts.

- Government and other stakeholders in early childhood development (ECD) in Nigeria should encourage local resource development initiatives through offering of sponsorship and other incentives;

- Collaboration efforts between researchers and stakeholders in ECD among governmental agencies like EFA, UBE, NITDA and local and international NGO's, should be encouraged towards the development, implementation and evaluation of indigenous instructional multimedia resources.

- The i-CLAP model in its present state has obvious technical limitations, which require further improvement, with a view to standardizing its structure and contents as a potential indigenous resource and advocating its integration into the Nigerian educational curriculum.

\section{References}

[1] ADEA (2004). ADEA's Executive Summary on DEOL in Sub-Saharan Africa.

[2] Amory, A., Naicker, K., Vincent, J. \& Adams, C. (1999). The Use of Computer Games as an Educational Tool: Identification of Appropriate Game Types and Game Elements. British Journal of Educational Technology. Vol. 30, No. 4, pp 311-321.

http://www.cblt.soton.ac.uk/multimedia/PDFsMM09/Use\%20of\%20computer\%20games\%20as\%20a n\%20educational\%20tool\%20identification\%20of\%20appropriate $\% 20$ game $\% 20$ types\%20and $\% 20 \mathrm{ga}$ me\%20elements.pdf

[3] Azi, J. I. (2005). “i-CLAP”: Developing An Indigenous Multimedia Model for Nigeria. An Unpublished Ph.D. Seminar Paper, Presented to UNICEF/NGO Committee on Education, UNICEF House, New York-USA.

[4] Azi, J. I. (2007). Interactive Child Learning Aid Project (i-CLAP). Developing an Indigenous Multimedia Model for Enhancing Pre-Primary Education in Nigeria. An Unpublished Ph.D. Thesis, Department of Industrial Design, Ahmadu Bello University (ABU), Zaria, Nigeria.

[5] Azi, J. I. (2012). Appraising the Role of Afrimation (African-Animation) in Promoting Africa's Rich Cultural Heritage in a Digital Age. International Journal of Computer Graphics \& Animation (IJCGA). Vol. 2, No. 2/3, July. http://airccse.org/journal/ijcga/papers/2212ijcga03.pdf

[6] Chambers, J. A. and Sprecher, J. W. (2007). Computer Assisted Instruction: Current Trends and Critical Issues. Volume 23, Issue 6 (June 1980), pp 32 - 342. SN: 0001-0782. ACM Inc. York, NY, USA.

[7] ECD: Sesame Workshop (2004). Sesame Street in West Africa: A Feasibility Study. American Institutes for Research (AIR). http://pdf.usaid.gov/pdf_docs/PNADD971.pdf

[8] European Commission (2012). Impact Assessment. http://ec.europa.eu/governance/impact/index_en.htm

[9] Igbuzor, O. (2007). The State of Education in Nigeria. http://www.dawodu.com/igbuzor14.htm

[10] Kinyanjui, P. E. (2012). Development of NEPAD e-Schools Initiative http://www.cedol.org/wpcontent/uploads/2012/02/179-185-2007.pdf 
International Journal of Computer Graphics \& Animation (IJCGA) Vol.2, No.4, October 2012

[11] Kronemann, M. (2007). Education is the Key: An Education Future for Indigenous Communities in the Northern Territory. Australian Education Union (AEU).

http://www.aeufederal.org.au/Publications/Educationisthekey.pdf

[12] Martins, A. A. (2007). Utilization of Computer Technology for Instruction in Nigerian Schools. Multidisciplinary Journal of Research Development (MULJORED), Published by National Association for Research Development (NARD) Markudi. ISSN 1596-974X. Vol. 8. No. 1, pp 119125 .

[13] MCEETYA (2000). A Model of More Culturally Inclusive and Educationally Effective Schools. Ministerial Council on Education, Employment, Training and Youth Affairs (MCEETYA). http://www.mceecdya.edu.au/verve/_resources/model_file.pdf

[14] McLoughlin, C. (1999). Culturally Inclusive Learning on the Web. In K. Martin, N. Stanley and N. Davison (Eds), Teaching In the Disciplines/Learning in Context, 272-277. Proceedings of the $8^{\text {th }}$ Annual Teaching Learning Forum, The University of Western Australia, February 1999. Perth: UWA. http://lsn.cutin.edu.au/tlf/tlf1999/mcloughlin.html

[15] McNutt, L. (1994). Developing Computer Aided Learning Resources for Tertiary Education: A Review and Synthesis of Current Research. Department of Computing, Regional Technical College, Ireland.

[16] Meyer, A. and Rose, D. (2007). Learning to Read in the Computer Age. CAST, Inc. Harvard Mills Square, MA.

[17] Morse, R. H. (2000). Computer Uses in Secondary Science Education. ERIC Digest. ERIC Clearinghouse on Information Resources Syracuse NY.

[18] Muppet Central News (2002). South Africa's Sesame Street Gets HIV+ Muppet. Associated Press. http://www.muppetcentral.com/news/2002/091702.shtml

[19] Neill, J. (2005). John Dewey: Philosophy of Education. http://www.wilderdom.com/experiential/JohnDeweyPhilosophyEducation.html

[20] Njanji, S. (2011). With Yams, Mosquito Nets: Nigeria Adapts Sesame Street. AFP. http://www.google.com/hostednews/afp/article/ALeqM5inkJEomlZn24WQmG1PU9KD mJeltw?docId=CNG.b31410b1a6b8da4e2332a60563c95985.2a1.

[21] Nordhoff, H. I. (2002). The Design and Implementation of a Computer-based Course Using Merrill's Model of Instructional Design. Med (CIE), Mini-dissertation, University of Pretoria.

[22] Nwachuku, M. A. (n.d.). Development of Information Technology in Nigeria. http://www.unu.edu/unupress/unupbooks/uu19ie/uu19ie0d.htm

[23] Okpaku, J. (2002). Background Paper on ICT-for-Development in Africa. United Nations ICT Task Force. http://www.unicttaskforce.org/thirdmeeting/documents/Background\%20Paper\%20on\%20ICTfor-Development\%20in\%20Africa\%20-\%200kpaku.htm

[24] Pence, A. \& Shafer, J. (2006). Indigenous Knowledge and Early Childhood Development in Africa: The Early Childhood Development Virtual University, Journal for Education in International Development 2:3. Retrieved from www.equip123.net/jeid/articles/4/IndigenousKnowledgeandtheECDVU.pdf. 
International Journal of Computer Graphics \& Animation (IJCGA) Vol.2, No.4, October 2012

[25] Indigenous Multimedia and Web Projects (2006). Rightside Response: Sharing and Managing Sensitive information. Rightside Response Pty Ltd Adelaide.

http://www.rightside.com.au/Indigenous_Web_Multimedia.php

[26] UNESCO (2003). "Communiqué of the Ministerial Round-Table on Quality Education”. UNESCO's General Conference 32nd Session. Accessed on March 26, 2006 at: http://portal.unesco.org.

\section{Author}

Dr. Joseph Izang Azi is a Lecturer with the Department of Industrial Design (Graphics), Ahmadu Bello University, Zaria, Nigeria. He is currently a Master's Degree student in Computer Graphic Design at the College of Imaging Arts and Sciences, Rochester Institute of Technology, Rochester, New York, where he was both a Fulbright and MacArthur Fellows in 2006 and 2008 respectively. He initiated the Interactive Child Learning Aid Project (i-CLAP) model design in 2002 as a Ph.D. research and defended the dissertation in 2007. The research result has been presented in several local and international conferences. This paper is an extract from one of such presentations; it was made at the $7^{\text {th }}$ Annual Conference of Fulbright Alumni Association of Nigeria (FAAN), Benin - Nigeria. 